\title{
Bioinformatics of Profilin in Wheat
}

\author{
Jingming $Q u^{1,2^{*}}$, Xiaohui Zhang1,2*, Xingyue Jia ${ }^{1,2}$, Rong Han ${ }^{1,2}$ \\ ${ }^{1}$ School of Life Science, Shanxi Normal University, Linfen, China \\ ${ }^{2}$ Higher Education Key Laboratory of Plant Molecular and Environmental Stress Response, Shanxi Normal University, Linfen, China \\ Email:775677995@qq.com
}

How to cite this paper: Qu, J.M., Zhang, X.H., Jia, X.Y. and Han, R. (2016) Bioinformatics of Profilin in Wheat. Open Journal of Immunology, 6, 181-188. http://dx.doi.org/10.4236/oji.2016.64017

Received: December 7, 2016

Accepted: December 27, 2016

Published: December 30, 2016

Copyright $\odot 2016$ by authors and Scientific Research Publishing Inc. This work is licensed under the Creative Commons Attribution International License (CC BY 4.0). http://creativecommons.org/licenses/by/4.0/

\begin{abstract}
Profilin is a small actin-binding protein that is essential in all organisms. While the wheat genome sequence database is not currently available, the exploration of bioinformatics is very important. Therefore, this article predicted the structure and function of profilin in wheat by bioinformatics methods. The amino acid sequence of profilin was searched in GeneBack. While its signal peptides were analyzed through CBS prediction server, the hydrophobicities were analyzed by bioedit software, we used EMBnet server and DNAstar to analyse the transmembrane domains and the B-cell epitopes of the profilin respectively. Finally, the tertiary structure of the protein was predicted through Swiss-Model. This information will help develop rational strategies to improve the component-resolving diagnosis and immunotherapy of profilin allergy.
\end{abstract}

\section{Keywords}

Wheat, Profilin Allergic, Bioinformatics

\section{Introduction}

Profilins are ubiquitous and abundant cytosolic proteins of $12-15 \mathrm{kDa}$, found in all eukaryotic cells [1] [2] [3] and virus [4]. They are key regulators of actin cytoskeleton dynamics through their interaction to monomeric actin (G-actin), and to a plethora of actin-binding proteins, which involve poly-L-proline (PLP) stretches [5]. Moreover, interaction with phosphatid ylinositol-4,5-bisphosphate, a major component of cellsignaling transduction pathways, is essential for the integration of stress responses through cytoskeleton rearrangement, in addition to processes such as cell movement and cytokinesis driven by actin polymerization dynamics [6]. Profilin was firstly recognized as an allergen (called Bet v 2) in birch pollen [7] and later described as allergen in

\footnotetext{
*These authors contributed equally to this work.
} 
plant foods and latex [8]. The wide spread cross-reactivity of profilins has led to the designation of profilins as "pan-allergens" [9]. The sensitization to these allergens has been considered as a risk factor for allergic reactions [10].

Wheat (Triticum aestivum L.) is one of the major food grains consumed by humans [11]. The economic and social significance of wheat is derived from its broad production and superior ability to generate diverse foods .However, ingestion of wheat can induce immune-mediated adverse food reactions such as celiac disease or IgE mediated Type 1 allergies in predisposed individuals. The prevalence of wheat induced food allergy is low in adults. However, in young children wheat is one of the major causes of food allergy. Respiratory allergy to wheat flour, affecting particularly persons working at bakeries and therefore named baker's asthma, is one of the most common causes of occupational asthma [12]. Recently, wheat profilin, designated Tri a 12, has been found to be recognized by specific IgE antibodies in patients suffering from baker's asthma.

In the present study, we predicted the structure and studied its influence over the structure of the profilin in wheat by bioinformatics methods. We have carried out an extensive analysis of the B-cell epitopes, to unravel profilin-specific epitopes, providing a comprehensive understanding of the broad cross-reactivity and specific allergy reactions to profilin. The knowledge provided in this study will help develop rational strategies to improve the component-resolving diagnosis and immunotherapy of profilin allergy.

\section{Method}

The amino acid sequence of the wheat profilin protein can be found in the NCBI website (http://www.ncbi.nlm.nih.gov/protein/CAA61945.2); the signal peptide is analyzed by CBS prediction server login (http://www.cbs.dtu.dk/services/, select signal P method) and the hydrophobic protein is predicted by bioedit Sequence Alignment Editer. Besides, we use EMBnet server (http://www.ch.embnet.org/, select TMPRED method) and DNAstar (http://www.dnastar.com/) to analyse the transmembrane domains and the B-cell epitopes of the protein respectively.

We predict the secondary structure of the wheat profilin on espasy proteomics website (http://www.expasy.org/tools/, select SOPMA method); use Swiss-Model to predict the tertiary structure of the protein (http://www.swissmodel.expasy.org/, select Automatic Modelling mode).

\section{Result}

\subsection{Analysis of Gene Function}

Amino acid sequence of profilin protein searched in the NCBI gene bank as follows: MSWKAYVDDHLCCEIDGQNLTSAAILGHDGSVWAQSPNFPQFKPEENAGIVKDF EEPGHLAPTGLFLGGTKYMVIQGEPGVVIRGKKGTGGITIKKTGMALILGIYDEPM TPGQCNLVVERLGDYLIDQGY.

\subsubsection{Prediction of the Signal Peptide}

The active site of the protein was predicted by ScanProsite method. We predict that 93 
and 111 are threonine phosphorylation sites; 6 and 12 are tyrosine phosphorylation sites (Figure 1). The glycosylation sites are $19-21$. The predictions of a signal peptide is shown in Figure 2, in which we can find the score in 35 is the highest, so 1 - 35 are predicting to be the signal peptide of profilin.

\subsubsection{Analysis of Protein Hydrophobicity and Transmembrane Domain}

Protein transmembrane region is the region about 20 hydrophobic amino acid residues and generally shows $\alpha$-helix structure. Using Bioedit software to predict protein's hydrophobicity, the score is more than 0 , with the increasing of the value, the representative of hydrophobic is better. As shown in Figure 3, the profilin protein's hydrophobicity is poor, and there is no a hydrophobic space of more than consecutive 20 amino

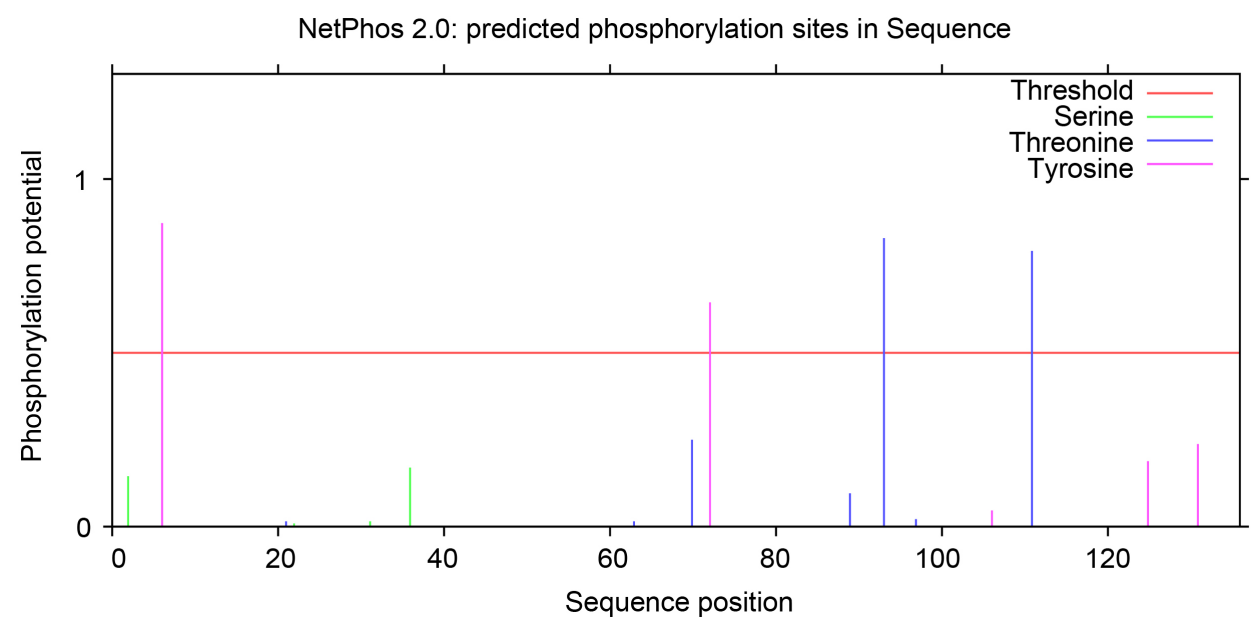

Figure 1. Prediction of the phosphorylation sites for profilin protein.

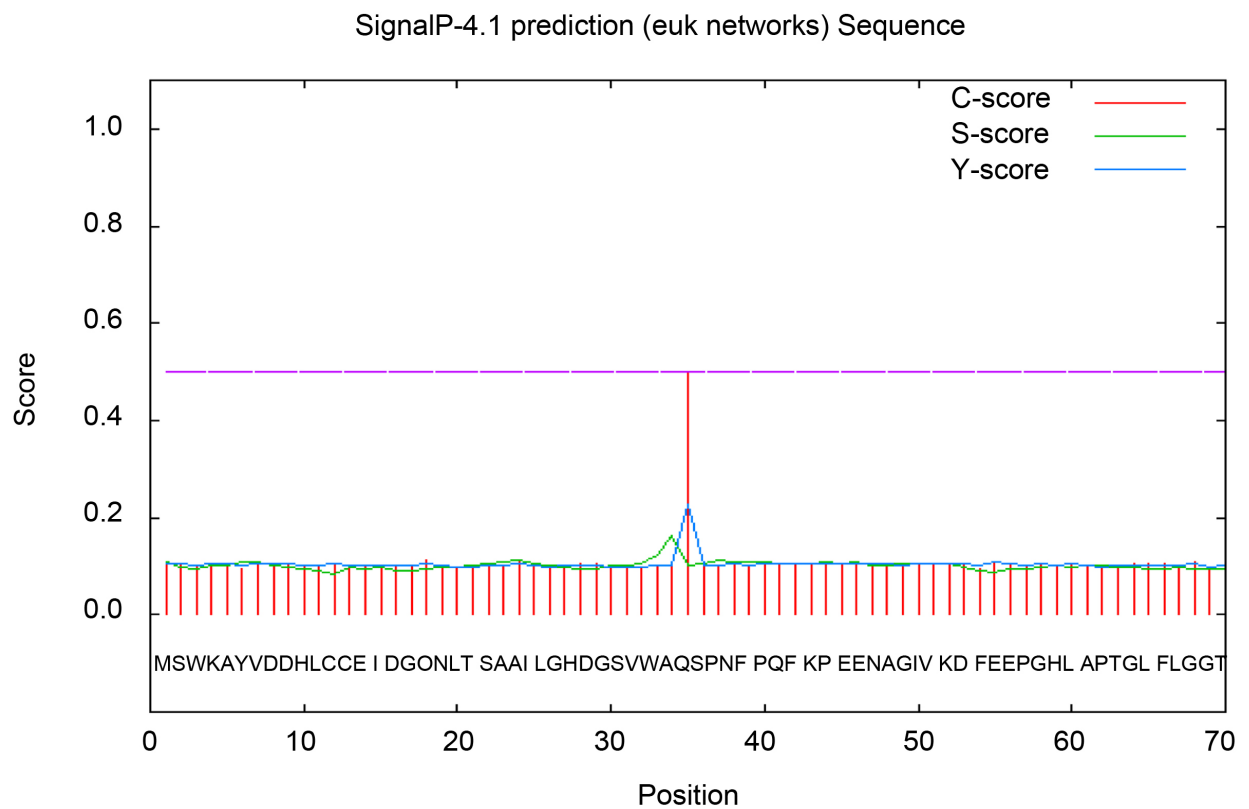

Figure 2. Prediction of the signal peptide for profilin protein. 
acids, which indicates that the protein does not exist transmembrane structure area. Figure 4 is using EMBnet server to predict transmembrane region. In general, if the score of the sequence of amino acids is positive, the region will be the transmembrane area of the protein. So Figure 4 shows that the wheat profiln protein does not exist transmembrane region.

\subsection{Analysis Structure}

\subsubsection{Analysis of the Secondary Structure}

Predicting the secondary structure of profilin protein in wheat is using SOPMA method. The result is shown in Figure 5. The relative content of $\alpha$-helix is $19.8 \%$; $\beta$-fold relative content is $30.53 \%$. The relative content of $\beta$-fold is higher than $\alpha$-helix.

\subsubsection{Analysis of the Tertiary Structure}

We find a Profilin-5 protein of which homology can reach $83.21 \%$ of wheat profiling

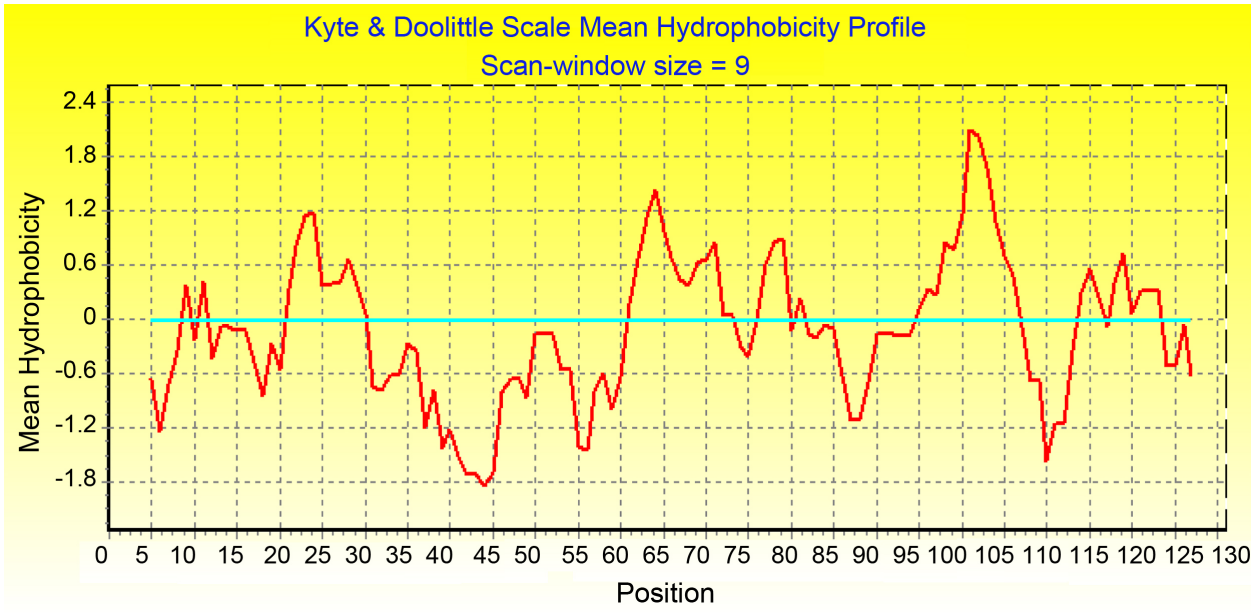

Figure 3. Prediction of the hydrophobicity for profilin protein.

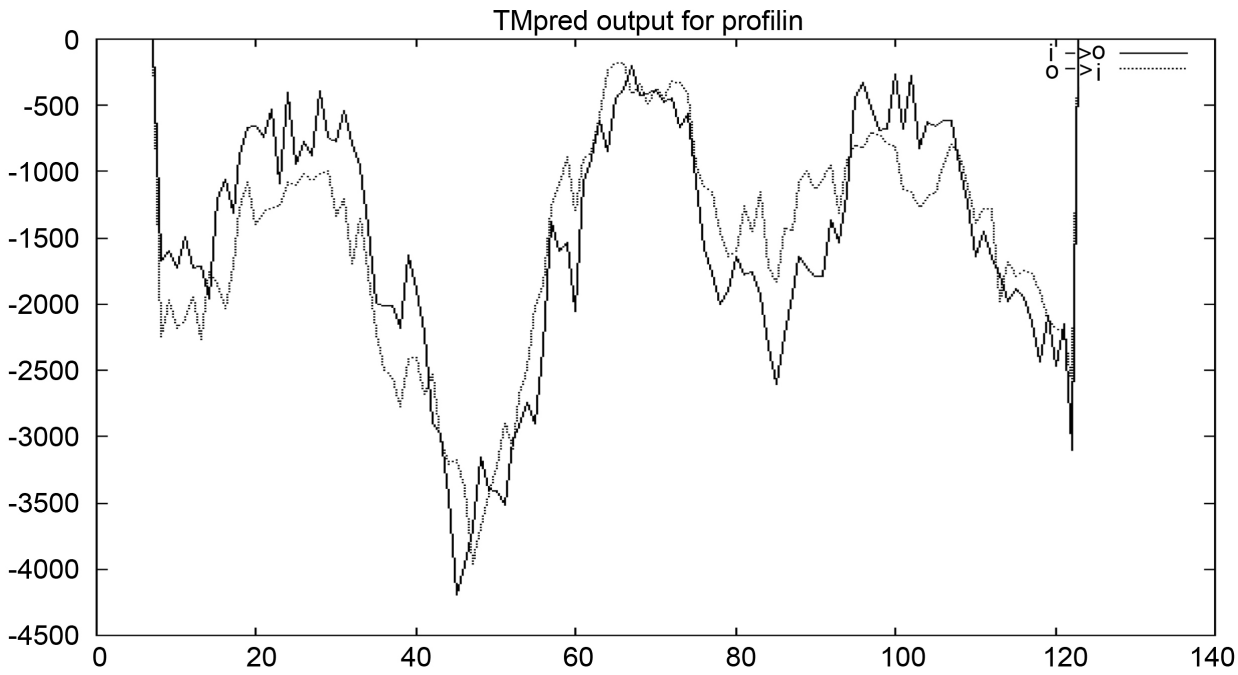

Figure 4. Prediction of the transmembrane domains in profilin protein. 
protein by PDB structure database (http://www.rcsb.org/pdb/home/home.do), the number of the PDB is 5fef.1.A. Meanwhile wheat profilin protein is predicted by Swiss-Model, as shown in Figure 6, we find wheat profilin protein has three helical domains that is all at the edge of the protein structure, and in the middle region of the protein is as a whole $\beta$-sheet structure area, which highly consistent with the predicted secondary structure in relative content of $\alpha$ helices and $\beta$ fold.

\subsection{Analysis of the Profilin Epitope of B-Cell}

As shown in Figure 7, Wheat profilin protein's hydrophilic, surface accessibility and antigen index are predicted by DNAstar software. There are three lines in the figure, which respectively is hydrophilic, antigenic index and surface accessibility from top to bottom. Upper and lower of horizontal lines represent the range of values that are important factors to determine the epitope of protein epitopes. When the surface accessibility is more than 1 , antigenic index is more than 0 , and surface accessibility is more than 1; amino acid residue region of the protein may form epitopes. The region of amino acids $40-47,53$ - 57 and 108 - 112 can be inferred to be antigen region of profilin protein through the various parameters and all of them are located on the surface, among which the number of the $40-47$ is located on the first $\alpha$ helice, the region of

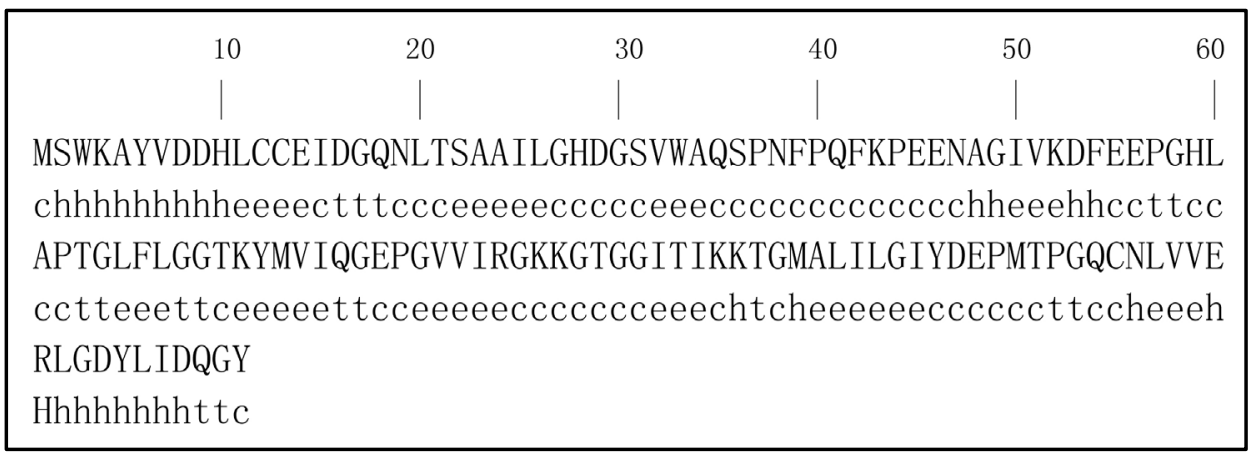

Figure 5. c.h.e and $t$ refer to coil.helix.extend strand and beta turn respectively.

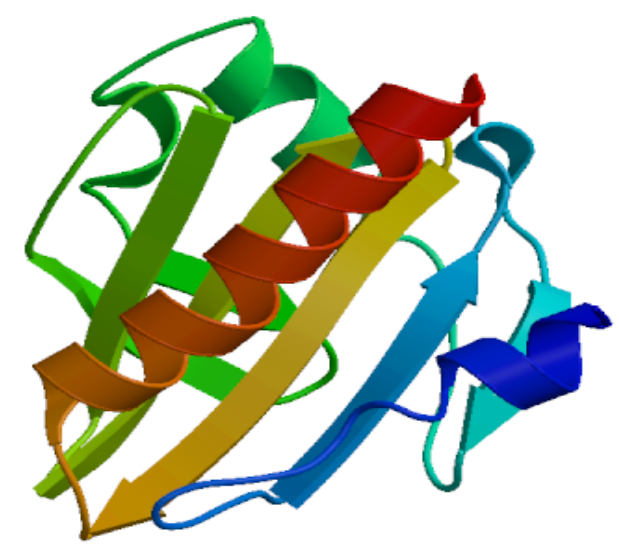

Figure 6. Swiss-model prediction result of tertiary structure of profilin protein. 


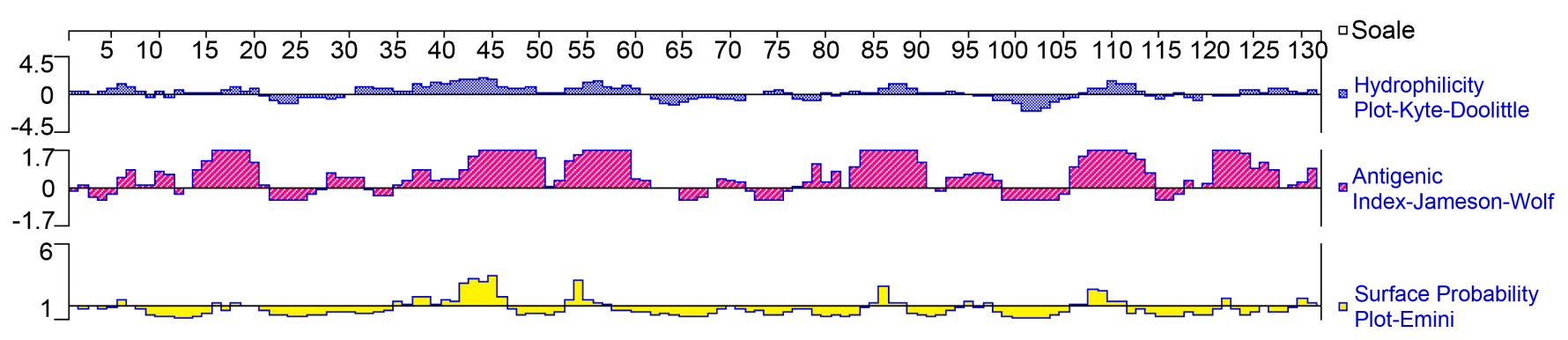

Figure 7. DNAstar prediction result.

53 - 57 connect with $\beta$ fold, and the area of $108-122$ connects with the last segment of $\alpha$ helices. According to the conditions of the request for $\mathrm{B}$ cell epitope, the region of amino acids 40 - 47, 53 - 57 and 108 - 112 may have high possibility to be a region of $\mathrm{B}$ cell epitope.

\section{Conclusions}

In this paper, the signal peptide of profilin was predicted by CBS prediction software and we found the region of $1-35$ is a signal peptide of profilin protein. Meanwhile, the profilins have a glycosylation site and a number of phosphorylation sites. Then, the hydrophobicities and transmembrane domains of profilin were analyzed by bioedit and EMBnet software. We had known that the hydrophobicities of profilin are poor, and there are no transmembrane domains. The content of secondary structure of profilin is calculated by establishing the model of secondary structure. The result shows that the profilins contains a lot of beta folding structure. Besides, the relative content of the alpha helix and beta folding are more than 15\%. Finally, the segments of $40-47,53-57$, and 108 - 112 may be a region of B cell epitope by using DNAstar software and the homology of profilin protein and Arah5 protein that have 3 segments of $\alpha$ helix domain can reach $79.07 \%$ by homology comparison. The results of this study are similar to those of Peanut profilin that was analysed by Xiao Jie in 2011 [13].

Allergic disease is one of the major problems in the current world of hygiene. Plant pollen and food play an important role in allergic reactions. The wheat can also cause severe allergic reactions. Recent studies have found that wheat could induce the patient's allergies to food and gas through the profiling-Tri a12 which have been identified by specific IgE antibody on the surface of bread workers [14]. Profilins are one of the most prevalent plant protein families causing IgE mediated reactions [15]. How to change the structure of wheat profilin protein or amino acid residues that can reduce the binding force of IgE and affect the immune response so as to reduce the allergy, is the fundamental method to solve the problem of wheat allergy. So, this article analyzes the structure and function of profilin using bioinformatics methods, which is the basis for further study on the allergic reaction of wheat cross reactivity and the sensitivity of profilin protein.

Bioinformatics aims at understanding the biological meaning of data, using biological tools to quickly predict the structure and functional properties of proteins. Profilin 
is a kind of actin binding protein which can regulate microfilaments and has a great important role in the biological growth and development, so there has certain theoretical significance and practical value of the application of bioinformatics analysis of the structure and function of profilin in wheat [16].

\section{References}

[1] Wilkes, D.E. and Otto, J.J. (2003) Profilin Functions in Cytokinesis, Nuclear Positioning, and Stomatogenesis in Tetrahymena Thermophila. Journal of Eukaryotic Microbiology, 50, 252-262. https://doi.org/10.1111/j.1550-7408.2003.tb00130.x

[2] Polet, D., Lambrechts, A., Ono, K., Mah, A., Peelman, F., Vandekerckhove, J., et al. (2006) Caenorhabditis Elegans Expresses Three Functional Profilins in a Tissue-Specific Manner. Cytoskeleton, 63, 14-28. https://doi.org/10.1002/cm.20102

[3] Witke, W. and Kwiatkowski, D.J. (2001) Profilin Is Essential for Cell Survival and Cell Division in Early Mouse Development. Proceedings of the National Academy of Sciences, 98, 3832-3836. https://doi.org/10.1073/pnas.051515498

[4] Blasco, R., Cole, N.B. and Moss, B. (1991) Sequence Analysis, Expression, and Deletion of a Vaccinia Virus Gene Encoding a Homolog of Profilin, a Eukaryotic Actin-Binding Protein. Journal of Virology, 65, 4598-4608.

[5] Schlüter, K., Jockusch, B.M. and Rothkegel, M. (1997) Profilins as Regulators of Actin Dynamics. Biochimica et Biophysica Acta, 1359, 97-109.

https://doi.org/10.1016/S0167-4889(97)00100-6

[6] Jimenez-Lopez, J.C., Rodríguez-García, M.I. and Alché, J.D. (2013) Analysis of the Effects of Polymorphism on Pollen Profilin Structural Functionality and the Generation of Conformational, t- and b-Cell Epitopes. PLOS ONE, 8, 377-380.

https://doi.org/10.1371/journal.pone.0076066

[7] Valenta, R., Duchêne, M., Pettenburger, K., Sillaber, C., Valent, P., Bettelheim, P., et al. (1991) Identification of Profilin as a Novel Pollen Allergen; Ige Autoreactivity in Sensitized Individuals. Science, 253, 557-560. https://doi.org/10.1126/science.1857985

[8] Valuer, P., Balland, S., Harf, R., Valenta, R. and Deviller, P. (1995) Identification of Profilin as an Ige-Binding Component in Latex from Hevea brasiliensis: Clinical Implications. Clinical \& Experimental Allergy, 25, 332-339. https://doi.org/10.1111/j.1365-2222.1995.tb01051.x

[9] Asero, R., Mistrello, G., Roncarolo, D., Amato, S., Zanoni, D., Barocci, F., et al. (2003) Detection of Clinical Markers of Sensitization to Profilin in Patients Allergic to Plant-Derived Foods. Journal of Allergy \& Clinical Immunology, 112, 427-432. https://doi.org/10.1067/mai.2003.1611

[10] Hauser, M. (2010) Panallergens and Their Impact on the Allergic Patient. Allergy, Asthma \& Clinical Immunology, 6, 1-14. https://doi.org/10.1186/1710-1492-6-1

[11] Hung, P.V., Maeda, T., Miyatake, K. and Morita, N. (2009) Total Phenolic Compounds and Antioxidant Capacity of Wheat Graded Flours by Polishing Method. Food Research International, 42, 185-190. https://doi.org/10.1016/j.foodres.2008.10.005

[12] Houba, R., Doekes, G. and Heederik, D. (1998) Occupational Respiratory Allergy in Bakery Workers: A Review of the Literature. American Journal of Industrial Medicine, 34, 529-546. https://doi.org/10.1002/(SICI)1097-0274(199812)34:6<529::AID-AJIM1>3.0.CO;2-I

[13] Xiao, J., Xuli, W.U., Wang, L. and Jun, L.U. (2011) Bioinformatics of Profilin Protein from Peanut. Immunological Journal, 27, 158-161. 
[14] Constantin, C., Quirce, S., Poorafshar, M., Touraev, A., Niggemann, B., Mari, A., et al. (2009) Micro-Arrayed Wheat Seed and Grass Pollen Allergens for Component-Resolved Diagnosis. Allergy, 64, 1030-1037. https://doi.org/10.1111/j.1398-9995.2009.01955.x

[15] Hoffmann-Sommergruber, K. and Mills, E.N.C. (2009) Food Allergen Protein Families and Their Structural Characteristics and Application in Component-Resolved Diagnosis: New Data from the Europrevall Project. Analytical and Bioanalytical Chemistry, 395, 25-35. https://doi.org/10.1007/s00216-009-2953-z

[16] Jianhua, X.U. (2005) Bioinformatics and Its Application on Protein Structure and Function Prediction. Foreign Medical Sciences, 2, 227-232.

Submit or recommend next manuscript to SCIRP and we will provide best service for you:

Accepting pre-submission inquiries through Email, Facebook, LinkedIn, Twitter, etc. A wide selection of journals (inclusive of 9 subjects, more than 200 journals)

Providing 24-hour high-quality service

User-friendly online submission system

Fair and swift peer-review system

Efficient typesetting and proofreading procedure

Display of the result of downloads and visits, as well as the number of cited articles

Maximum dissemination of your research work

Submit your manuscript at: http://papersubmission.scirp.org/

Or contact oji@scirp.org 